\title{
Sistema de fijación de metas inflacionarias de la política monetaria de Nueva Zelandia2
}

\section{Introducción}

El autor agradece la invitación a presentar este seminario sobre el sistema de fijación de metas inflacionarias de Nueva Zelandia en el Banco de Corea. Constituye, para el autor, un gran honor. Si bien ahora es Director Ejecutivo del Banco Mundial por Corea, Nueva Zelandia, Australia y otros nueve países, antes fue subgobernador del Banco de Reserva de Nueva Zelandia antes de ir a Washington D.C. hace un año. En total trabajó durante 23 años en el Banco de Reserva de Nueva Zelandia, así que se considera un especialista en banca central.

\section{Antecedentes}

A mediados de 1986, el entonces Ministro de Finanzas de Nueva Zelandia, Roger Douglas, dijo que estaba dispuesto a darle al banco central independencia operativa si podíamos desarrollar un proceso por medio del cual el gobierno de turno - y el público- pudiera hacernos responsables. El autor estuvo a cargo del grupo de trabajo que se organizó para formular dicho marco.

Este trabajo dio como resultado la Ley del Banco de Reserva de Nueva Zelandia de 1989, que fue sancionada en diciembre de 1989 y establece el marco de política monetaria que ha sido aplicado desde entonces en Nueva Zelandia.

Cuando la ley fue tratada en el Parlamento en 1989, contó con el respaldo del gobierno y de la oposición. Cuando fue aprobada, no hubo votos en contra. Estos detalles los da a conocer por tres razones:

(a) La Ley del BRNZ fue el resultado de un proceso largo y cuidadoso de dos años y medio. Estudiamos la legislación extranjera sobre la banca central; revisamos la teoría monetaria; consultamos ampliamente dentro de Nueva Zelandia y a otros bancos centrales y académicos en el extranjero. Es importante llevar a 
cabo un proceso completo y cuidadoso porque es difícil introducir cambios una vez que se tiene ya establecido el nuevo marco. Por un lado, podría afectarse la credibilidhd que el marco haya logrado si se hace necesario cambiarlo rápidamente o de manera muy sustancial.

(b) El marco de política monetaria adoptado era consistente con las reformas que estaban aplicándose en todo el sector público de Nueva Zelandia, que tenían por objeto lograr objetivos claros, incrementar la responsabilidad y, donde había responsabilidad y objetivos claros, proporcionar a los jefes de los organismos gubernamentales una mayor independencia operativa.

(c) La ley y el marco de política monetaria contaron con amplio apoyo político. Esto es importante. Si ese respaldo no existe, entonces por bien intencionado, hábil y decidido que sea el banco central en la implementación de la política monetaria, la política no tendrá la credibilidad necesaria y habrá amplias expectativas de que esta meta no durará.

\section{Las razones}

¿Por qué adoptamos este enfoque de política monetaria en Nueva Zelandia? Creo que habían tres razones principales ${ }^{3}$ :

En primer lugar, gran parte del ímpetu por el nuevo marco derivó de que habíamos tenido muchos más años de inflación que nuestros socios comerciales. Entre 1967, cuando iniciamos nuestra montaña rusa de inflación/devaluación, y 1986, cuando el nivel de precios en Nueva Zelandia se infló hasta cerca de 1000 por ciento, alrededor de $21 / 2$ veces el promedio de nuestros socios comerciales.

Si bien la inflación puede dispararse inicialmente por una diversidad de causas, sólo puede persistir por tanto tiempo ocurrió en Nueva Zelandia si las autoridades monetarias lo permiten. Esa inflación tan elevada y variable socavó la calidad de la inversión y el crecimiento y condujo a una pronunciada caída de nuestro lugar en los cuadros de riqueza a nivel mundial.

En segundo lugar, ya se hallaba en camino un amplio proceso de reforma pública integral en Nueva Zelandia y la revisión del BRNZ fue vista, en parte, como una aplicación de ese proceso de revisión al banco central. (Por ejemplo, al tiempo que obtuvimos independencia en materia de política operativa, perdimos cierta independencia financiera.)

En tercer lugar, había una amplia aceptación internacional acerca de que lo máximo que podía razonablemente esperarse de la política monetaria era un control a mediano plazo sobre la inflación. Existe bastante consenso internacional acerca de que los efectos de las medidas de política monetaria sobre el producto y el empleo no son lo suficientemente predecibles ni permanentes como para que el "manejo" del producto y el empleo sea un objetivo realista de la política monetaria. El resultado final de tratar de lograr estos objetivos con la 
política monetaria tiende a ser más inflación, pero crecimiento escaso o no sostenido.

El problema principal con la antigua legislación del Banco de Reserva con la que operaba el Banco desde 1964, era que la política monetaria podía tener diversos objetivos y estos objetivos podrían ser, y eran, cambiados frecuentemente. La legislación de 1964 decía que la política monetaria “deberá orientarse al mantenimiento y la promoción del bienestar económico y social en Nueva Zelandia, teniendo en cuenta el deseo de promover el mayor nivel de producción, comercio y pleno empleo, y de mantener un nivel de precios internos estables". Suena bien. ¿Quien podría estar en contra de esto? El problema es que dicho marco conduce a cambios erráticos en el enfoque de la política monetaria y no proporciona ninguna base para juzgar si esta política monetaria ha sido bien o mal implementada. Como su Gobernador Asistente dijo hoy en el almuerzo, contar con estos objetivos múltiples de una política monetaria es como tratar de perseguir a tres o cuatro conejos simultáneamente. El resultado más probable es que no se logre cazar a ninguno.

\section{El marco}

¿Cuáles son las características principales del marco de política monetaria en Nueva Zelandia? El autor ha distribuido varias páginas de un antiguo discurso suyo que las explica brevemente .

(a) La política monetaria en Nueva Zelandia tiene por objeto lograr la estabilidad de precios. Esto en sí mismo no es raro ni profundo. El objetivo declarado de la política monetaria de muchos países es la estabilidad de los precios. Lo que es único del enfoque de Nueva Zelandia es la claridad y transparencia de los papeles respectivos del gobiemo y del banco central, la manera en la cual se fija la meta, la especificación detallada de esta meta y las formas que asume la responsabilidad del BRNZ.

(b) La ley establece en la Cláusula 8 que "la función principal del Banco es formular e implementar políticas monetarias dirigidas al objetivo económico de lograr y mantener la estabilidad en el nivel general de precios". Esta cláusula reemplazó a la cláusula con objetivos múltiples. La ley no decide el término estabilidad de precios. Pero requiere el establecimiento de un contrato formal y público entre el Ministerio de Finanzas y el Gobernador del Banco Central, al que se refiere como el Acuerdo de Metas de Política (AMP). Esto define este término. El famoso objetivo (o infame, dependiendo del punto de vista) del 0-2 por ciento de inflación subyacente está establecido en el AMP y no en la ley.

Dentro de los términos de la ley, el Ministerio de Finanzas puede encomendar al Gobernador que tome en cuenta otros de los objetivos económicos además de 0 , incluso, en sustitución de la estabilidad de precios. Sin embargo, dichas directivas tienen que ser formales, públicas y caducan después de doce meses a 
menos que sean renovadas. El Ministerio no ha utilizado estas atribuciones desde que fue sancionada la ley en 1989.

(c) Ló que esto significa es que la determinación del objetivo de la política monetaria se mantiene firmemente en las manos del gobiemo. Creímos, y todavía creemos, que en una democracia parlamentaria como la de Nueva Zelandia, el gobiemo elegido debe tener el derecho de ejercer, en última instancia, el control de los objetivos de la política económica.

$A$ veces se ha descrito al BRNZ como el banco central más independiente del mundo. Si bien esa descripción es muy halagadora, cuando se determina el objetivo de la política monetaria es, sin embargo, equivocada. El gobiemo determina el objetivo.

(d) Una vez se ha acordado y publicado el AMP, el gobernador del BRNZ tiene completa independencia para la formulación diaria de la política monetaria. Nótese que dicha atribución corresponde al gobernador y no al banco central. El gobiemo quería tener a alguien claramente responsable.

(e) La ley no otorga al BRNZ el poder de imponer controles directos sobre las tasas de interés o las directrices sobre préstamos. No creíamos necesitar dichos poderes para poder lograr la meta. Sin embargo, es importante para un banco central que está buscando o se le ha ofrecido independencia operativa, que tenga confianza en que cuenta con suficientes instrumentos de política monetaria para poder lograr este objetivo de política. Lo que constituye "suficiente" en este sentido variará de un país a otro y aun dentro de un país cambie a lo largo del tiempo a medida que se desarrollan los mercados financieros del país.

Operamos la política monetaria a través de mecanismos de mercado. Realizamos operaciones diarias de mercado abierto. Operamos en el mercado monetario interno. No hemos intervenido directamente en el mercado cambiario desde que el dólar de Nueva Zelandia comenzó a flotar en marzo de 1985.

$(f)$ No tenemos ninguna "meta" financiera intermedia a la cual vinculamos nuestras operaciones de política monetaria. La única "meta" es la tasa de inflación. En el lenguaje del antiguo debate sobre reglas o discrecionalidad en la política monetaria, la meta es una "regla" pero implementamos la política sobre una base "discrecional".

Sin embargo, el nivel del tipo de cambio y las tasas de interés a corto plazo son importantes variables operativas.

(g) La meta se especifica como el logro de una inflación de 0 a 2 por ciento en función del Índice de Precios al Consumidor (IPC) a lo largo de cada período de 12 meses, después de ajustar estas "advertencias" específicas con el fin de tener en cuenta los shocks de oferta. Algunas características de esta forma de especificaciones son las siguientes: 
- Se utiliza el IPC porque es el índice de precios más ampliamente conocido y comprendido. No es una medida teóricamente perfecta de las variaciones en el nivel general de precios, pero tampoco lo son ninguna de las alternativas.

- La banda de la meta no está centrada en cero. Está centrada en el 1 por ciento. Existen varias razones por las cuales una cifra algo superior al cero en el IPC podría ser consistente con una estabilidad de los precios: el tipo de índice utilizado, la metodología de encuesta utilizada, la dificultad de tener en cuenta nuevos bienes o mejoras en la calidad. No determinamos "específicamente" que el 1 por ciento es el ajuste apropiado para estas características. Es una estimación aproximada.

"El uso de "advertencias" significa que estamos utilizando como meta una medida de la inflación "subyacente" más que la inflación publicada. La lista de "advertencias", sin embargo, se especifica en el AMP por adelantado. El BRNZ no puede escoger su propia formulación y agregar o sustraer "advertencias" a medida que van sucediendo. Las tres "advertencias" se relacionan con: (a) cambios en impuestos indirectos y cargos gubernamentales; $(b)$ cambios significativos en los precios intemacionales de las exportaciones e importaciones de Nueva Zelandia, y (c) los efectos de la variación de las tasas de interés sobre el IPC.

Han habido algunas críticas acerca del hecho que el BNRZ sea quien mide la inflación subyacente en vez de hacerlo una agencia independiente. El BRNZ ha dedicado muchos esfuerzos a la explicación de los conceptos y la medición de esta medida objetivo que es la inflación subyacente.

(h) Responsabilidad. La responsabilidad corresponde al Gobernador. Pero yo, como subgobemador, tengo un contrato con él, y el Economista Jefe tiene un contrato conmigo. Entonces la responsabilidad cae en cascada a través de toda la organización.

Los principales mecanismos de la responsabilidad son:

- Un requisito de publicar una Declaración de Política Monetaria por lo menos cada seis meses. El BRNZ esencialmente publica dichas declaraciones cada trimestre. Las mismas exigen que el banco pronostique la economía, la posible trayectoria inflacionaria y la respuesta de la política monetaria ante esas perspectivas. Este marco pone mucha presión y responsabilidad sobre aquellas personas que realizan los pronósticos económicos.

- El banco puede ser examinado por un Comité del Parlamento después de la publicación de cada declaración. Eso ha sucedido todas las veces hasta ahora. 
Si bien éstos son los mecanismos formales de responsabilidad, la transparencia del objetivo y de las operaciones de la política monetaria significan rque el banco y el Gobernador constantemente están siendo juzgados por los mercados financieros y el público en general. Reciben muchos consejos y algunas críticas.

(i) La principal sanción por el mal desempeño es la potestad explícita del Ministro de Finanzas de destituir al Gobemador. En un discurso que el actual Gobemador, Don Brash, pronunció recientemente en Estados Unidos, dijo:

Puedo asegurarles que la combinación de un contrato público y la responsabilidad formal de producir resultados de acuerdo con ese contrato, proporcionan incentivos muy poderosos para que el Gobernador se asegure de que las decisiones de política monetaria sean, realmente, consistentes con el AMP. Quizá tan importante es el hecho de que esta misma estructura proporciona restricciones igualmente poderosas sobre los políticos que ocasionalmente quisieran tener un poco más de latitud en la conducción de la política monetaria ${ }^{5}$.

\section{Los resultados}

¿Qué es lo que ha sucedido en la práctica? El autor no dará una descripción detallada, sino que tratará de explicar las principales características y enseñanzas de los últimos seis años de operación de este marco.

En primer lugar, los resultados inflacionarios en este período de seis años han sido mucho mejores que en los veinte años anteriores. La inflación se ha mantenido en un nivel de alrededor del 7 por ciento cuando se aprobó la ley (había alcanzado un promedio de cerca del 14 por ciento durante la mayor parte de los años setenta y ochenta). Como puede verse en la gráfica que se ha distribuido, se mantuvo dentro de la meta de 0 a 2 por ciento en 1992 y básicamente se ha mantenido en el mismo nivel, excepto durante el período actual. La cifra de junio de 1992 fue de 2,2 por ciento. El BRNZ espera llegar a un máximo del 2,6 por ciento en septiembre de 1996, mantenerse fuera del objetivo durante todos los trimestres de 1996 y luego volver a mantenerse dentro del objetivo.

La primera vez que superó el objetivo ocurrió poco después de que el autor fue a Washington (es pura coincidencia. Debido a los desfases, las decisiones pertinentes de política se habían adoptado antes, cuando él estaba ahí).

El Gobernador no ha sido destituido a pesar de que no se logró el objetivo. No es coincidencia. Es el resultado de una revisión cuidadosa por parte del directorio del Banco y el Ministro de Finanzas acerca de la naturaleza del marco y el desempeño del Gobemador. Quienes hubieran querido que se destituyera al Gobernador, y hay algunas, querían que saliera porque ha sido demasiado duro. La destitución por exceder un poco el objetivo, sin embargo, sería destituirlo porque no ha sido lo suficientemente duro. 
En segundo lugar, el comportamiento cambió en respuesta a este marco, pero no inmediatamente. No pareció haber un gran efecto de anuncio. Requirió un esfuerzo constante y consistente por parte del banco central y el gobierno para cambiar este comportamiento. Así que me temo que la experiencia de Nueva Zelandia respalda el viejo adagio de que las acciones hablan más que las palabras. El banco central tiene que ganarse la credibilidad. Creo que el BNRZ ahora tiene mucha credibilidad. Por ejemplo, hay una clara disminución en las expectativas inflacionarias de Nueva Zelandia. Estas expectativas ahora están ancladas en bajos niveles de un solo dígito.

En tercer lugar, el marco, particularmente su objetivo claramente definido y su transparencia y sus disposiciones sobre responsabilidad, tienen un impacto muy visible sobre la manera en la cual el Banco de Reserva enfoca la formulación de la política monetaria. El Gobernador, Don Brash, cree "que las decisiones difíciles fueron tomadas anteriormente y presentadas antes con mayor fuerza de lo que hubiera ocurrido con los estatutos anteriores (del Banco)" está de acuerdo con él.

En cuarto lugar, estas mismas disposiciones del marco han tenido un visible impacto sobre la manera en que los políticos piensan y hablan de la política monetaria. Casi todos aceptan la estabilidad de los precios como el objetivo apropiado de la política monetaria. No todos apoyan la especificación actual del objetivo pero "nadie percibe ventajas electorales en abogar por la tolerancia de una inflación mayor que un solo dígito. Los límites superiores de esta tolerancia inflacionaria podrían variar entre el 2 por ciento y algo más cerca, quizá, del 3,5 por ciento, pero esto claramente representa un cambio sustancial con respecto al tipo de niveles que se consideraban aceptables antes de $1989^{7}$ ".

En quinto lugar, el marco establecido para la política monetaria en Nueva Zelandia ha producido otro "interesante subproducto" . Éste es una reducción aparente en la volatilidad del tipo de cambio. Si bien Nueva Zelandia tiene un tipo de cambio flotante, y no ha habido una intervención directa en el mercado cambiario desde la flotación en marzo de 1985, el Banco de Reserva ajusta su política monetaria para procurar y asegurarse de que el tipo de cambio se mantenga dentro de límites consistentes con el mantenimiento de la inflación dentro de este nivel objetivo. El mercado claramente comprende este proceso.

Este podría considerarse como una meta intermedia del tipo de cambio, pero el empleo de esta descripción puede ser fácilmente mal interpretada: nuestra "meta" cambiaria o "zona de comodidad" está altamente condicionada a lo que está sucediendo con las presiones inflacionarias. El resultado neto de enfocar la implementación de la política monetaria de esta manera parece haber sido un tipo de cambio que es relativamente estable, en el sentido de su variabilidad de mes a mes, pero relativamente flexible. Hasta ahora, por lo menos hemos logrado evitar la variabilidad "excesiva" y de alta frecuencia de los tipos de cambio 
flotantes enteramente libres y sin límites, y también hemos evitado los problemas de los tipos de cambio extremadamente rígidos ${ }^{y}$.

Por úlfimo, se han producido otros cambios significativos en el comportamiento del mercado financiero como consecuencia de este marco. Antes que todo, ha habido cambios significativos en el comportamiento del banco central. Algunos ejemplos importantes son:

* El debate de la política monetaria dentro del Banco es mucho más claro porque todos llegan al mismo con las mismas funciones de objetivo. Durante algunos años el autor presidió el Comité de Política Monetaria que se reunía semanalmente en el Banco de Reserva. En el antiguo marco, las diferencias de puntos de vista eran difíciles de resolver o aun de analizar porque los participantes muy a menudo tenían diferentes sistemas de ponderación (generalmente sin haberlos especificado) para los objetivos múltiples. Contar con un objetivo claro y no ambiguo no significa que todos estén de acuerdo con la acción apropiada, si solamente la formulación de la política monetaria fuera tan fácil. Pero las diferencias de puntos de vista se relacionan con las diferencias sobre el estado futuro de la economía, los vínculos entre las condiciones de la política monetaria y la inflación futura, etc., y pueden estar sujetos a análisis.

* La capacidad para pronosticar la economía, y en especial la inflación, con una exactitud razonable se ha convertido en algo muy importante. La credibilidad del Banco de Reserva depende tanto de su capacidad para pronosticar como de su resolución en materia de política.

* El Banco de Reserva ha asignado un fuerte énfasis en la divulgación pública y la educación. En una democracia, los políticos solamente pueden continuar respaldando un marco como el de Nueva Zelandia si existe un grado suficientemente razonable de comprensión del público y de respaldo al mismo.

En segundo lugar, el comportamiento del resto de los mercados financieros ha variado en respuesta a los cambios en el comportamiento del banco central. Los mercados se han vuelto aliados del banco central en la implementación de la política. La mayor parte de las actividades de mercado son estabilizadoras en el sentido de que desplazan las condiciones en una dirección que es consistente con la dirección del banco central querría. ¿Por qué ha sucedido esto? Los mercados comprenden bien el marco. El banco central permite que el mercado desplace su tasas de interés a corto plazo, lo que es la principal variable operativa de la política monetaria. La tasa de descuento se fija como un margen sobre la tasa interbancaria, no como un nivel. El mercado puede aumentar o disminuir la tasa de descuento. El Banco de Reserva tiene que validar tales movimientos. En la mayoría de las ocasiones, ello no requiere ninguna acción por parte del banco central, ya que el mercado ha actuado adecuadamente. 
Como consecuencia de este comportamiento del mercado, el banco central ha tenido que adoptar algunas medidas explícitas de política monetaria, aunque periódicamente interviene ligeramente en el mercado con lo que se ha llegado a conocer como "operaciones de boca abierta", es decir una declaración por parte del Gobernador o de algún otro funcionario.

Pero este comportamiento del mercado se basa en la creencia del mercado de que el banco central actuaría si fuera necesario. Ocasionalmente, el banco central tiene que respaldar sus palabras con acciones para poder mantener su credibilidad. Un ejemplo fue a principios de enero de 1993, cuando después de 18 meses en los que no se había producido ningún cambio formal en las políticas monetarias, se anunciaron tres cambios de política en un día -a las 8:00 am, a las 10:30 am y a las 2:00 pm - para poder contrarrestar presiones muy fuertes a la baja en el tipo de cambio, que amenazaban la meta inflacionaria.

\section{Conclusión}

¿Cambiaría algún elemento del marco si estuviera en condiciones de hacerlo? El autor piensa que haría solamente un cambio. Cree que las dificultades inherentes en el logro de la precisión en los pronósticos económicos y las incertidumbres en los desfases entre las variaciones en la situación monetaria y la inflación, implican que la especificación de la meta como de 0-2 por ciento en todo momento es demasiado estricta.

Existen dos opciones para el cambio: (a) una banda más amplia y $(b)$ una meta específica como el promedio a lo largo de un período (es decir, un ciclo económico) en vez de en todo momento.

El autor cree que este último cambio sería preferible. Se relaciona más estrechamente con los problemas que cree han llevado a la "sobreespecificación". Por tal razón, es más probable que sea percibido por los mercados financieros y el público como un cambio técnico sensato más que un debilitamiento de la decisión de mantener una estabilidad de precios que una ampliación de la banda objetivo.

En general, el marco ha constitutido un gran éxito para Nueva Zelandia. Por tanto, el autor recomendaría el modelo general para otros países. Sin embargo, los detalles específicos deben analizarse cuidadosamente para poder satisfacer determinadas circunstancias específicas políticas, económicas y de mercado financiero. Es importante considerar estos detalles en forma adecuada, o casi adecuada al anunciarse un nuevo marco, ya que la introducción de cambios posteriores hará que sea más difícil y costoso lograr la credibilidad. 


\section{Notas}

1. Director Ejecutivo del Banco Mundial.

2. Este seńninario fue presentado en el Banco de Corea, Seúl, Corea, el 23 de agosto de 1996. [N. del E. Esta ponencia ha sido adaptada para presentarla por escrito.]

3. Marco de Estabilidad de Precios, presentación hecha ante la Sociedad de Contadores de Nueva Zelandia por Peter Nicholl, Gobernador Asistente, BRNZ, el 27 de noviembre de 1990.

4. Discurso del 27 de noviembre de 1990 , véase la nota 2.

5. Discurso pronunciado por Don Brash, Gobernador del RVNZ, en el Banco Federal de Reserva de Kansas City, Jackson Hall, Wyoming, Conferencia, agosto de 1996.

6. Véase la nota 4.

7. Véase la nota 4.

8. Véase la nota 4.

9. Véase la nota 4. 